\title{
Marcelo Caetano y los desarrollistas españoles: la liberalización de los no liberales
}

\author{
Juan Carlos Jiménez Redondo \\ Universidad San Pablo-CEU
Marcelo Caetano and the Spanish «desarrollistas»: The Liberalization of Non Liberals

\begin{abstract}
RESUMEN
Las diferentes vías de los procesos de transición a la democracia en Portugal y España hunden sus raíces en la diversa suerte que corrieron los proyectos de liberalización del autoritarismo en cada país. El marcelismo constituyó una serie de oportunidades perdidas porque en realidad siempre fue difícilmente compatible con el poder personal que

Salazar en todo momento reclamó. Fracasó en los años cuarenta y primeros cincuenta porque se presentó como alternativa y porque apareció demasiado pronto, cuando el régimen seguía inmerso en una fuerte tensión política. Fracasó a inicios de los sesenta porque no pudo resistir la presión derivada de las necesidades de Salazar de acudir a una permanente tensión política e ideológica es decir, nacionalista- para cohesionar de nuevo la dictadura en torno él. El desarrollismo español triunfó porque se presentó como solución adecuada para satisfacer las necesidades de estabilidad y equilibrio del franquismo y del propio Franco, en un momento de evolución de la dictadura hacia un marco más burocrático y progresivamente menos ideologizado y politizado. Pero, en definitiva, en ambos casos, es evidente
\end{abstract}

\begin{abstract}
The different ways from the transition processes from the democracy in Portugal and Spain sink their roots in the diverse luck that ran the projects of liberalization of the authoritarianism in each country. The "marcelismo" constituted a series of lost opportunities because in fact was hardly compatible with the personal power that Salazar always claimed. It failed in the Forties and first fifies, because it appeared as an alternative and because it turned out too much soon; when the regime was still immersed in a strong political tension. It failed at beginnings of the sixties because it could not resist the pressure derived from Salazar's needs of coming to a permanent political and ideological tension -that's to say, nationalist- to draw together the dictatorship around him. The Spanish development policy prevailed because it appeared as suitable solution adapted to satisfy the needs of stability and balance of the Franco's regime and of the own Franco, in a while of evolution of the dictatorship towards an ideologized and politicized more bureaucratic frame and progressively fewer ideologism and despoliticided one. But, definitively, in both cases, it's evident that the authoritarian regimes generate routes of liberalization
\end{abstract}


que los regímenes autoritarios generan

vías de liberalización que sin ser ellas mismas democráticas, pueden encauzar un proceso de transición hacia la democracia cuando convergen con otros procesos y factores que coadyuvan a esa evolución.

PALABRAS CLAVE:

Portugal y España. Dictaduras y reformismos. Fracaso del reformismo marcelista. Éxito del «desarrollismo» español. Transición a la democracia that without being democratic they themselves, they can channel a process of transition towards the democracy when other processes and factors converge with that evolution.

KEYWORDS:

Portugal and Spain. Dictatorship and Reformism. Failure of Caetano's Reformism. Success of Spain's "desarrollismo». Transition to Democracy

\section{CAMBIO Y MODERNIZACIÓN EN UN RÉGIMEN AUTORITARIO}

En abril de 1974 la Revolución de los Claveles puso fin al régimen autoritario portugués encarnado, entonces, por Marcelo Caetano. El golpe militar inició un proceso de transición por ruptura, que supuso acabar de forma explícita con el marco legal establecido por el régimen autoritario, simbolizado con la salida del dictador hacia el exilio. Poco más de un año después, la muerte del general Franco dio lugar a la coronación del Rey Juan Carlos y al inicio de un proceso de transición política por reforma, que permitió alcanzar la democracia partiendo de la legalidad proveniente del régimen autoritario.

Resulta paradójico, pues, que los procesos de transición siguieran en ambos países peninsulares caminos tan diferenciados y aparentemente contradictorios. La debilidad institucional del franquismo dio lugar a un complejo proceso de reforma y ruptura, pero siempre dentro de un contexto de evolución «de la ley a la ley». Sin embargo, el acabado marco institucional del Estado Novo portugués originó un proceso rupturista y de derribo aparentemente súbito del régimen autoritario.

Esta perceptible paradoja podría llevar, en principio, a minusvalorar los factores de evolución institucional de los regímenes autoritarios como elementos fundamentales de cambio político, aceptando, incluso, que éstos no influyen decisivamente en la naturaleza ni en la forma que adopta un determinado proceso de transición política. Si esto fuera así, es decir, si los factores político-institucionales no fueran especialmente significativos como motor del cambio político, habría que volver a las explicaciones más clásicas que consideran que las raíces del cambio político están, más bien, en los factores de transformación social y económica que acaban modificando la cultura política de las sociedades autoritarias hasta convertirlas en sociedades abiertas y receptivas a la democracia. $\mathrm{O}$, incluso, habría que considerar que la transición es un proceso separado de la evolución del autoritarismo y que, por tanto, no tiene sus raíces en él, pues éste constituiría una especie de etapa histórica cerrada en sí misma. 


\subsection{Los factores de cambio}

La correlación entre cambio socioeconómico y cambio político no presenta una causalidad tan lineal como tradicionalmente se pensaba. Más bien, recientes experiencias asiáticas e incluso africanas llevan a pensar que la relación puede ser inversa y que es la democracia la que estimula el desarrollo socio-económico. En realidad, el desarrollo económico y el cambio social que éste genera pueden tener un efecto contradictorio, pues es verdad que en algunos casos estimula un proceso de transición democrática, pero en otros pueden tener como consecuencia el mantenimiento del autoritarismo político. La actual experiencia china es bien demostrativa de ello.

Modernización económica sin cambio político es, en efecto, un proceso perfectamente compatible, por lo menos a corto y medio plazo, aunque exige una serie de reformas liberalizadoras que acaban socavando tanto las propias bases institucionales del autoritarismo, como acaban disgregando sus apoyos sociales, afectando con ello a los equilibrios fundamentales que permiten su mantenimiento. Pero el que esos equilibrios internos se vean afectados, no significa que los regímenes autoritarios carezcan de instrumentos para recomponerlos o, incluso, que puedan crear nuevos equilibrios que les permitan mantenerse. De hecho, tanto el salazarismo como el franquismo son ejemplos perfectos de la capacidad de adaptación de las dictaduras a diferentes contextos internos y externos. Más bien indican la capacidad de los regímenes autoritarios para realizar un juego de adaptaciones permanentes sin necesidad de socavar de forma irreversible ninguno de los principios fundamentales en los que se basan.

El pragmatismo y la flexibilidad son los factores que explican la adaptabilidad demostrada por muchos regímenes autoritarios, especialmente los de la Península Ibérica, para mantenerse durante tantos años, y los que les aparta de los regímenes totalitarios.

Estos factores se concretan en, primero, la limitación — que no desapariciónde los vínculos jurídicos del poder político, pues aunque en ningún caso se puede hablar de un Estado de derecho, sobre todo por el uso de métodos despóticos de control social, el poder se ejerce dentro de límites formalmente mal definidos, pero predecibles. En segundo término, una concepción restrictiva de las libertades civiles que no llega a su supresión completa, pues existe un cierto reconocimiento de los derechos individuales y se mantiene la idea de una sociedad diferente al Estado. En tercer lugar, la existencia de un cierto pluralismo político limitado, pues aunque se suelen prohibir los partidos políticos y otras organizaciones sociales -por ejemplo, los sindicatos libres-, se permiten algunas expresiones ideológicas autónomas. En cuarto lugar, y esto es esencial, la ausencia de una ideología rectora claramente establecida, pues más bien hay algunos valores fundamentales en los que coinciden amplias capas de apoyo a la dictadura. En quinto término, inexistencia de una movilización política intensa y extensa excepto en algunos momen- 
tos puntuales. Por último, el papel secundario del partido único, que actúa más como captación de las elites de poder que como verdadera organización que asalta el Estado. Es un Estado con partido único, no un partido único que se apropia del Estado

Evidentemente, el pragmatismo y la flexibilidad permiten a los autoritarismos una alta capacidad de adaptación, lo que aumenta enormemente sus expectativas de permanencia, pero al mismo tiempo, son elementos que tienden a erosionar su cohesión interna y los equilibrios sociales sobre los que se sustentan, lo que, evidentemente, estimula factores potenciales de disgregación que pueden incrementar las posibilidades de que se produzca un cambio político.

Todas estas contradicciones llevan a pensar que, en realidad, los procesos de transición a la democracia son procesos abiertos que se van alimentando a si mismos, y que se producen por una concatenación compleja de causas que no siempre son las mismas. Del mismo modo, tampoco es perceptible un modelo que permita deducir la forma concreta que va a adoptar un determinado proceso de transición. Como mucho se podrían señalar algunos factores de estabilidad que ayudarían a que ese proceso pudiera adoptar un camino no disruptivo, pero la importancia de expectativas y factores no tangibles hace muy difícil extraer patrones fiables para elaborar cualquier categoría teórica rígida. En realidad, los procesos de transición a la democracia son bastante abiertos, específicos y dependientes de la coyuntura concreta en la que se desarrollan.

En todo caso, aunque sea difícil encontrar relaciones causales rígidas, sí es posible encontrar elementos susceptibles de coadyuvar a que esa puerta al cambio pueda abrirse de forma definitiva. $Y$ entre ellos, hay que incluir los cambios políticoinstitucionales que experimentan los regímenes autoritarios, cuya incidencia será más decisiva si coexiste con procesos de cambio social y de modernización económica.

\subsection{El cambio sin cambio}

Lo curioso es que estas posibilidades de cambio suelen ser abiertas desde dentro del autoritarismo por sectores que buscan a través de la liberalización y la apertura el arraigo social del régimen. $O$ dicho de otra forma, suelen ser sectores con un criterio jurídico profundo, que pretenden sustituir las fórmulas clásicas de control social basadas en la utilización extensiva de mecanismos e instrumentos represivos, por una fórmula de estabilización basada en la desmovilización socio-política y en la adhesión pasiva al régimen. Esta nueva vía de regulación del sistema autoritario se sustenta, a su vez, en las expectativas de bienestar personal y colectivo propiciadas por un desarrollo económico progresivo y en criterios de seguridad jurídica a través de mecanismos de objetivación de la relación entre el ciudadano y el poder político autoritario. 
Desde esta perspectiva, la dictadura tiende a convertirse en un régimen ordenado y de participación selectiva, que a cambio de trabajar por el «bien común» aunque sea un término inadecuado dado que ese bien común excluye a una parte significativa de la población- monopoliza los mecanismos de ejercicio del poder político.

Las corrientes liberalizadoras y modernizantes son, en definitiva, productos que genera el propio régimen para cumplir las demandas de adecuación a las cambiantes coyunturas históricas, siempre sobrevenidas y muy pocas veces buscadas. La función básica de estos modernizadores es acomodar los regímenes autoritarios a las nuevas demandas que se generan desde arriba - provenientes del sistema internacional — o desde abajo, —las propias de una sociedad modernizada y en cambio. Y lo hacen desde posiciones más o menos ortodoxas dentro del régimen, pero en todo caso, desde dentro del régimen. Lo hacen con pretensiones de asentar el autoritarismo sobre unas bases más objetivas y racionales, pero en definitiva, con la finalidad de que el régimen autoritario pueda perdurar. Por tanto, es una reforma sin ruptura, un cambio que a corto y medio plazo no cambia nada sustantivo. Aunque a largo plazo, la esencia autoritaria queda sustancialmente puesta en cuestión por su actuación.

Por tanto, son desarrollistas o modernizadores que utilizan como instrumento de actuación la liberalización del régimen autoritario en distintas áreas y vertientes, pero no son liberales en absoluto, ni mucho menos demócratas. Pero el que su impulso no sea genuinamente democrático, no significa que no generen expectativas que sólo la democracia puede satisfacer. De hecho, su función de racionalización de las estructuras autoritarias y de objetivación de las relaciones entre la dictadura y los ciudadanos, crea un marco de progresiva burocratización del Estado que tiende a resquebrajar la identificación entre Estado y dictadura. O dicho de otra forma, y acudiendo a los criterios de legitimidad weberianos, tienden a sustituir los criterios de legitimidad carismática o tradicional por criterios de legitimidad legal-racional, propios de sociedades modernas y esenciales para que la democracia pueda asentarse.

Aquí es donde convergen los desarrollistas portugueses, liderados durante muchos años por Marcelo Caetano, y los desarrollistas españoles amparados bajo el manto protector del almirante Luis Carrero Blanco, aunque su cabeza más visible fuera Laureano López Rodó. No resulta pues, nada extraño que todos ellos partieran de una concepción parecida de la sociedad, ni que todos ellos tuvieran una profunda formación jurídica, o que todos ellos compartieran unas convicciones religiosas profundas. Por eso tampoco llama la atención que existiera entre ellos una fuerte empatía y una sólida amistad personal. Las diferencias serán, básicamente, de tiempo y de oportunidad política. 


\section{MODERNIZADORES Y LIBERALIZADORES EN PORTUGAL Y EN ESPAÑA}

\subsection{Autoritarismo estático y autoritarismos dinámicos}

Los autoritarismos ibéricos no pueden ser considerados como meros regímenes reaccionarios y estáticos, donde cualquier perspectiva de desarrollo estaba, sin más, ausente. Bien es verdad que el carácter de regímenes de modernización puede ser discutible, aún más en el caso del salazarismo que en el del franquismo, pero aún así, ninguno de ellos renunció a la modernización, aunque su naturaleza profundamente conservadora graduara excesivamente sus tiempos y su intensidad. De hecho, desde sus orígenes, ambos se presentaron como proyectos de regeneración material encuadrados ideológicamente dentro de unos determinados marcos políticos antilberales y antiparlamentarios. El problema es que durante los primeros años de ambas dictaduras, esa regeneración material se pretendió conseguir mediante un modelo autocentrado, casi autárquico, con muy poca capacidad para generar una masa de capital suficiente para acometer las inversiones necesarias y, en general, para propiciar una dinámica económica consistente, capaz de provocar un grado de desarrollo significativo.

El modelo semiautárquico que adoptaron, respondía básicamente a las concepciones nacionalistas de los dos dictadores y a sus planteamientos intervencionistas. Creían que el Estado debía desempeñar un papel fundamental en la organización de la vida económica, habida cuenta de que su antiliberalismo no sólo tenía una dimensión política, sino también económica. En realidad, la primacía de la política autoritaria, es decir, de la edificación y estabilidad de la dictadura mediante la imposición y el control social, llevó a una concepción muy limitada y claramente preventiva del concepto de desarrollo, concebido como un marco de control estatal dirigido a conseguir el grado de autosuficiencia material más alto posible, pues ambos regímenes siempre fueron conscientes de la imposibilidad de cerrar por completo sus economías al exterior.

La idea de desarrollo se concebía, pues, desde el Estado y para el Estado. El objetivo era generar un Estado fuerte y económicamente potente, no una sociedad basada en el bienestar de los ciudadanos.

El modelo no era, sin embargo, original o específico de los autoritarismos ibéricos, sino que se encuadraba en ese marco general de descrédito del capitalismo liberal propiciado por el hundimiento de la bolsa de Nueva York de 1929. En todas partes, la respuesta a la crisis fue una exacerbación del nacionalismo, del proteccionismo y del intervencionismo económico, que en algunos casos se orientó hacia la autarquía. El intervencionismo estatal alimentó un proceso de reforzamiento del poder ejecutivo sobre el legislativo, lo que reafirmó el giro hacia el autoritarismo emprendido por muchos países de la Europa central y meridional. 
El modelo semiautárquico y de industrialización dirigida generó algunos avances significativos, pero en general, dio como resultado una economía claramente ineficiente, carente de incentivos y ausente de criterios de competencia. La debilidad de las políticas fiscales hizo imposible acumular capital suficiente para acometer una política amplia de inversiones estatales. Las limitaciones del capital privado interno y las trabas impuestas a la entrada de capitales extranjeros tampoco permitieron una renovación tecnológica suficiente para hacer a las empresas estatales competitivas.

En realidad, el proteccionismo lo que creó fue un proceso de cartelización empresarial, más acabado en Portugal que en España, que agudizó la concentración del capital y la relación simbiótica entre el poder económico y el poder político como base de sustentación de los equilibrios básicos que mantenían ambas dictaduras.

La inexistencia de un cambio económico profundo impidió un cambio social significativo. Durante sus primeros veinte años, ambas dictaduras fueron incapaces de crear condiciones mínimas de bienestar social, por eso el recurso a los mecanismos coactivos fue en este período más extendido, sobre todo en la dictadura española. Cierto es que a mediados de los cincuenta algunos índices socioeconómicos habían mejorado algo, pero, en general, las condiciones de vida seguían siendo precarias en ambos países. Llama especialmente la atención lo sucedido en Portugal, pues la notable mejoría experimentada por la economía durante los años de la Segunda Guerra Mundial, apenas había repercutido en la población. Más bien, lo que había creado es un Estado solvente y equilibrado y un proceso de concentración monopolista muy acusado. Fue este esquema de Estado rico y población pobre el que desde mediados de los años cuarenta comenzó a alimentar a un sector crítico en el interior del salazarismo que consideraba necesario imprimir un nuevo impulso económico y político al régimen.

\subsection{Opciones liberalizadoras y resistencias}

Las tensiones liberalizadoras fueron, pues, bastante anteriores en Portugal que en España, lo que se explica por varias razones. En primer término, porque en Portugal la corriente liberalizadora apareció como reacción a lo que se consideró una cierta paralización y un relativo desviacionismo del régimen de sus bases originarias. Por eso no es extraño que fuera Marcelo Caetano quien liderara esta corriente, pues él había sido - junto al propio Salazar y a Pedro Teotónio Pereirauno de los grandes constructores de la estructura jurídica, política e institucional del Estado Novo. En España, sin embargo, los liberalizadores eran personas sin vinculación directa con la construcción original del régimen, por lo que gozaron de un amplio margen de actuación para recomponer la dictadura en un momento de profunda crisis, que generó una amplia percepción de que era necesario un profundo cambio para sacar al país de la práctica bancarrota. Marcelo Caetano nunca tuvo 
esa libertad, pues, en su opinión las deficiencias que demostraba el régimen eran debidas a que no se sacaba todo el partido posible a su estructura organizativa, jurídica e institucional. Podía interpretar lo que consideraba la verdadera esencia del régimen, pero difícilmente podía destruir lo que en gran parte había sido obra personal suya.

En segundo lugar, porque en España, los marcos institucionales eran flexibles y podían moldearse ampliamente siempre y cuando no fueran radicalmente contrarios a lo que Franco pudiera admitir. Las Leyes Fundamentales del franquismo crearon un cauce institucional suficientemente abierto como para permitir distintas prácticas políticas, pues la única limitación real era que no pusieran en cuestión la esencia del poder personal del jefe del Estado. En consecuencia, la práctica política podía cambiar siempre y cuando la capacidad de intervención directa de Franco disminuyera y se ampliara el margen de maniobra de los ministros y altos cargos de la Administración. O dicho de otra forma, cuando la dictadura tendiera hacia una creciente burocratización. Y de hecho, el cambio liberalizador coincidió con una notable disminución en el ejercicio del poder personal por parte de Franco, un alejamiento posible porque el cúmulo de problemas que tenía que afrontar la dictadura no afectaba ya a la permanencia del dictador en el poder.

En Portugal, sin embargo, aunque la estructura institucional era mucho más acabada y coherente, también era más abierta a la posibilidad del cambio, siempre y cuando se transformara esa relación de subordinación que la Constitución de 1933 establecía entre el presidente del Consejo de Ministros y el presidente de la República, por una relación real de jerarquía y dependencia de aquel respecto de éste. En otros términos, la dictadura de Salazar dependía, por lo menos institucionalmente, de que el presidente de la República nunca utilizara su poder teórico de nombramiento y destitución del presidente del Consejo. Y la experiencia histórica demuestra que esa posibilidad existió realmente en varios momentos fundamentales.

Este carácter híbrido de la dictadura portuguesa, obligaba a Salazar a una práctica política que le asegurara su permanencia en el poder, por lo que cualquier cambio no sólo debía contar con su aprobación, sino que debía ajustarse a sus propias necesidades de mantenerse en el poder. Por eso Salazar siempre concibió el cambio como un riesgo, no como una solución y por eso, siempre lo intento controlar y adecuar a un ritmo que el pudiera dominar. En definitiva, el marco institucional era efectivamente más abierto en el caso portugués que en el español, pero también más inseguro para el mantenimiento de la dictadura o, mejor dicho, para que Salazar mantuviera su poder personal.

Esto supuso que mientras que en España el cambio liberalizador y modernizador fue visto por Franco con reparos, pero, en cualquier caso, como una solución para el mantenimiento del régimen y, en última instancia, de su poder personal; en el caso portugués el cambio conllevaba altas dosis de inseguridad y prevención, pues la corriente liberalizadora y especialmente su líder, no fue siempre visto por 
Salazar como una simple solución meramente técnica, sino como un posible rival político para el mantenimiento del poder.

Además, mientras la posibilidad de liberalizar en España se dio en un momento de crisis, pero con un Franco ya definitivamente asentado en el poder, lo que aumentó su viabilidad, en Portugal apareció en una coyuntura de crisis, de efervescencia de la oposición y de cuestionamiento del poder personal de Salazar. Por eso nunca cuajó de forma total ni contó con el apoyo incondicional del dictador. Siempre utilizó a las facciones más reaccionarias como algo más que un contrapeso para ajustar los equilibrios políticos internos de la dictadura, porque Salazar siempre fue algo más que un mero árbitro moderador de los distintos intereses en presencia. Salazar no era un simple espectador situado por encima de las luchas internas. Salazar era un actor participante, más bien el actor fundamental, que encabezaba un grupo dominante dentro de la dictadura: el de la ortodoxia salazarista.

Franco en cambio nunca concibió a ninguno de los liberalizadores como una amenaza para su poder personal. Al contrario, el que los liberalizadores y modernizantes siempre fueran apoyados por Carrero Blanco, les permitió una libertad de movimientos realmente notable porque la relación entre Carrero y Franco se basó siempre en la total lealtad del primero y la absoluta confianza del segundo. Algo distinto de la relación respetuosa y en algunos momentos íntima, existente entre Salazar y Marcelo Caetano, pero en la que el factor confianza fue inestable.

Lo curioso es que esa prevención era seguramente exagerada, pues Marcelo Caetano siempre se consideró a sí mismo como un hombre de gobierno, pero no el hombre del gobierno. Carecía de dotes de liderazgo y muchos aseguran que no ambicionó el poder. Lo cierto es que cuando lo tuvo, lo consideró más una obligación que debía asumir que un deseo finalmente cumplido. Más que buscar ser la alternativa de Salazar, el problema de Marcelo Caetano fue aparecer siempre cercano a quienes podían hacer efectiva la sustitución del viejo dictador.

Pero tampoco conviene exagerar este punto. De hecho, las fuentes diplomáticas españolas, bastante bien informadas de los entresijos del poder en Lisboa, siempre señalan a Marcelo Caetano como el muñidor último de todas las posibilidades abiertas para sustituir a Salazar y, aunque seguramente exageran, tampoco cabe descartar que en muchas de ellas sí desempeñara un papel muy relevante. En todo caso, si bien es verdad que asumió el poder como una obligación moral, nunca rehusó ejercerlo, por lo menos hasta que comprobó que su gestión carecía de apoyos y que existía una alternativa militar que antes o después acabaría haciéndose con el poder.

Un último factor que conviene señalar es el relativo a la cuestión internacional. El final de la guerra había repercutido de forma diferente en ambos países y en ambos regímenes. Mientras el salazarismo se encontró ante los problemas lógicos de readaptación a un contexto internacional distinto, aunque potencialmente peli- 
groso, el franquismo recibió una rotunda condena, siendo apartado de todas las instituciones sustentadoras del nuevo orden de la posguerra. En este marco, cualquier evolución interna del régimen hubiera supuesto un evidente riesgo que Franco nunca estuvo dispuesto a correr, aunque, también es verdad, que ese cambio tampoco fue posible porque nunca existió entre los distintos círculos de la dictadura el consenso suficiente para marcar un único rumbo de evolución de la dictadura. El lema, un tanto primario pero muy efectivo, atribuido a Carrero Blanco de «paciencia y a aguantar» sólo admitía ciertos cambios cosméticos y una mayor insistencia en el ropaje católico que lo hiciera más presentable, pero impidió ir más allá. Es decir, el período de ostracismo internacional no permitió que Franco tomara en consideración la posibilidad de afrontar cambios liberalizadores profundos, aunque no impidió que afloraran algunas propuestas de evolución como la defendida por Alberto Martín Artajo, partidario por aquel entonces de que el régimen desembocara en una monarquía católica, corporativa y semiautoritaria. Sólo cuando Franco se aseguró de que su régimen estaba plenamente consolidado aceptó andar el camino de la liberalización y la modernización económica, Bien es verdad que más obligado por las circunstancias que por expresa voluntad propia.

\subsection{La oportunidad perdida de la liberalización del autoritarismo luso}

La capacidad de maniobra de Salazar no sólo fue mayor, sino que al no sufrir ninguna presión externa directa, pudo adoptar medidas liberalizadoras más importantes con el fin de relegitimar el régimen. Entre otras, y fundamentalmente, la convocatoria de elecciones legislativas, algo que evidentemente permitía la Constitución de 1933 y que en España era, simplemente, impensable. Aunque evidentemente el régimen acabó recurriendo a la fuerza de la coacción y a la manipulación electoral, Salazar consiguió abanderar las expectativas de una cierta apertura política, atrayéndose incluso a una parte considerable de la oposición, aunque el recurso a la fuerza acabó convenciéndola de la imposibilidad de participar en el marco de la dictadura. Pero la victoria no fue completa. Al ver los caminos de participación cerrados, la oposición se orientó hacia el golpismo, intentando seducir a figuras significativas de dentro de la dictadura, hasta el punto de que en algunos momentos llegaron incluso a enredar en estas tramas al propio presidente de la República. Salazar había demostrado un amplio control de la situación política, aunque tuvo que acceder a configurar un gobierno -el de febrero de 1947- en el que los sectores liberalizadores y los más ortodoxos y fieles a él pugnaban por dirigir la evolución del Estado Novo.

Salazar logró recomponer los equilibrios básicos de la dictadura, pero no logró una victoria completa. Tuvo que incorporar a los liberalizadores y darles una posición de relevancia en la orientación del régimen. Pero lo fundamental es que al fracasar la estrategia diseñada, curiosamente, por Marcelo Caetano, de incorporación selectiva de la oposición liberal dentro de las reglas políticas e institucionales del 
régimen, la facción liberalizadora que él encabezada pasó a desempeñar esa función, convirtiéndose en una especie de oposición al salazarismo, pero dentro del régimen del Estado Novo y con un proyecto que muy poco tenía de transformador de sus estructuras básicas.

En este marco de pugna larvada, el conflicto bipolar, esto es, la guerra fría, acabó actuando como factor aglutinador y sustentador del régimen y del poder de Salazar. Los liberalizadores tuvieron que conformarse con una estrategia de ocupación parcial y progresiva del poder hasta que las circunstancias les permitieran aflorar de nuevo. En todo caso, la coexistencia no impidió que esta corriente siguiera siendo percibida más como alternativa que como complemento del salazarismo, lo que acabó haciendo incompatible ambos proyectos o, mejor dicho, acabó generando la necesidad de que uno absorbiera a otro.

El momento crítico de este proceso fue la celebración de las elecciones presidenciales de 1958 y la irrupción en la escena política portuguesa del «terremoto Delgado». La propia negativa de Salazar a renovar la candidatura del entonces presidente Craveiro Lopes era ya un indicio claro de esta incompatibilidad. La predisposición del presidente de la República hacia el reformismo y la posibilidad de que éste anidara entre los círculos militares menos proclives a Salazar, alarmó al viejo dictador, que decidió prescindir de Craveiro Lopes, apostando por una figura meramente decorativa como la que representaba el Almirante Américo Tomas. Lo que Salazar nunca previó es que iba a surgir un candidato oposicionista radicalmente nuevo, con una sorprendente capacidad de convocatoria que le llevó a lograr concitar el apoyo entusiasta de millones de portugueses.

El delgadismo pudo acabar efectivamente con la dictadura de Salazar en 1958, pero realmente con quien acabó fue con Marcelo Caetano. Igual que en 1961 lo pudo hacer el golpe preparado por el ministro de Defensa con el apoyo de los principales jefes militares del Estado Novo, y también en ese momento el gran perdedor fue Marcelo Caetano, pues nunca pudo despejar la duda de haber estado maquinando en la sombra para ser el recambio preparado por los golpistas para sustituir a Salazar. Por tanto, lo que sucedió tras esa fecha fue que Salazar acabó con el reformismo marcelista. El nuevo reformismo sería el que él mismo aceptase y dirigiese. La guerra colonial iniciada en 1961 fue el factor decisivo que utilizó Salazar para cohesionar de nuevo la dictadura en torno a su persona. Salazar había conseguido una estabilidad inestable, pero suficiente para mantenerse firmemente en el poder hasta que un accidente vascular le apartó del poder. Sin Salazar, el régimen abrió de nuevo la puerta a Marcelo Caetano.

\subsection{La consolidación del franquismo}

Desde mediados de los años cuarenta, el franquismo fue gestionado con un doble objetivo: asegurar su estabilidad y seguridad en el marco de la guerra fría y garantizar su viabilidad a largo plazo por medio de su legitimación como monarquía 
y con Franco como una especie de regente vitalicio, en el que recaía el poder soberano del Estado. El régimen fue adquiriendo una rutina en el ejercicio del poder que ayudó tanto a su despolitización como a su burocratización.

El oscurecimiento de las actividades de la oposición y, en general, el convencimiento de los españoles de que no existía una alternativa viable al poder personal de Franco, acabaron por transformar la agenda política. Falange aparecía cada vez más desdibujada y los problemas de institucionalización de la dictadura parecían resueltos, por lo que la agónica bocanada falangizante de la crisis de 1956 y el posterior intento del proyecto institucional de José Luis de Arrese de 1957, acabaron curiosamente convenciendo a Franco de que el concepto de modernización de la dictadura debía ir más por la vía de los liberalizadores tecnócratas del Opus Dei que por la vía del ya sobrepasado ideario falangista. Los mecanismos de control social parecían haber tenido éxito si no en su misión de propiciar adhesiones masivas al régimen, sí en su función desmovilizadora. La burocratización y la progresiva complejidad de la sociedad y del mundo que se abría paso, acabaron por abrir la puerta al desarrollismo de los años sesenta.

La diferencia sustancial respecto de Portugal es que los desarrollistas no constituyeron nunca una alternativa de poder a Franco, porque sus perspectivas en este sentido, que sí las tenían, se proyectaban hacia el largo plazo. Es decir, los desarrollistas españoles creían en la evolución del régimen, pero su meta era la instauración de una monarquía de orden capaz de generar un marco de estabilidad política que gestionase las demandas de una sociedad, en buena medida desmovilizada y satisfecha por unas altas condiciones materiales de vida.

Los desarrollistas españoles plantearon sus propuestas como una posibilidad de superación de los históricos problemas sociales que había vivido España que era lo que, en su opinión, explicaba la gran inestabilidad política que había envuelto al país en los últimos dos siglos. Por tanto el desarrollo no sólo tenía como fin inmediato mejorar la economía española, sino que significaba la posibilidad de alcanzar una meta histórica: poner fin a la gran conflictividad que había caracterizado la historia contemporánea de España.

Los desarrollistas, pues, aunque tenían un horizonte político indudable, -siendo muy discutible que ese fin fuera la democracia- lo situaban después de Franco. La monarquía era una meta a la que había que llegar, parafraseando a López Rodó, tras una larga marcha que el país debía recorrer por el camino de la modernización económica y la estabilidad social y política.

Y así se planteó. Justo en el momento en el que tenía todas las oportunidades de triunfar, pues las demandas de un sistema internacional en cambio exigían unas respuestas nacionales que sólo se podían cumplir por medio de un cambio estructural profundo.

En definitiva, el marcelismo constituyó una serie de oportunidades perdidas porque en realidad siempre fue difícilmente compatible con el poder personal que 
Salazar siempre reclamó. Fracasó en los años cuarenta y primeros cincuenta porque se presentó como alternativa y porque apareció demasiado pronto, cuando el régimen seguía inmerso en una fuerte tensión política. Fracasó a inicios de los sesenta porque no pudo resistir la presión derivada de las necesidades de Salazar de acudir a una permanente tensión política e ideológica —es decir, nacionalistapara cohesionar de nuevo la dictadura en torno él. El desarrollismo español triunfó porque se presentó como solución adecuada para satisfacer las necesidades de estabilidad y equilibrio del franquismo y del propio Franco, en un momento de evolución de la dictadura hacia un marco más burocrático y progresivamente menos ideologizado y politizado.

\section{LAS DEMANDAS DEL SISTEMA INTERNACIONAL Y LAS ADAPTACIONES DEL AUTORITARISMO}

\subsection{La primacía de la seguridad}

La recomposición de los criterios de orden una vez finalizada la Segunda Guerra Mundial, se ajustaron a las dinámicas de polarización resultantes de las relaciones de poder establecidas entre las dos grandes superpotencias. En este espacio sistémico centrífugo, caracterizado por la bipolaridad, y al mismo tiempo intersistémico centrípeto, caracterizado por la homogeneización de cada uno de los bloques de poder, las posibilidades de actuación autónoma de las dictaduras ibéricas eran muy limitadas. Pero no sólo por estos condicionantes externos, sino también por su firme voluntad de insertarse en el sistema político y de seguridad del mundo occidental. La alternativa de la neutralidad era, en estos momentos, una posibilidad muy lejana.

La apuesta era perfectamente coherente en ambos casos, aunque la España franquista tuvo que conformarse con una incorporación indirecta y problemática al mismo, a través de acuerdos bilaterales directos con los Estados Unidos, a los que luego se incorporó Portugal. La guerra fría permitió, por tanto, la rehabilitación internacional del franquismo y su parcial inserción internacional. Y permitió también un impulso básico en las relaciones peninsulares al imponerse el concepto de unidad estratégica defensiva. En otros términos, los acuerdos hispano-norteamericanos de 1953 no fueron una mera tabla de salvación para el mantenimiento de la dictadura. Fueron, ante todo, la vía posible para que España pudiera cumplir funciones necesarias para la defensa occidental sin causar situaciones de quiebra dentro del sistema. Del mismo modo que la revisión estratégica realizada por el salazarismo tuvo poco que ver con la mera empatía política o ideológica. Más bien hay que relacionarlo con el problema de la seguridad del país - y no sólo de la dictadura - en un contexto donde la consideración del enemigo se había desplazado hacia el expansionismo soviético y las posibilidades de defensa individual o incluso bilateral —el recurso histórico a la Alianza Británica - se habían convertido en soluciones materialmente imposibles. 
Las demandas de seguridad del bloque occidental hacían necesario un reforzamiento de la cohesión interna de sus participantes. Por eso la guerra fría acabó estabilizando los regímenes autoritarios, porque su sustitución hubiera abierto un boquete de incertidumbres inaceptables en un momento donde las posibilidades de una guerra eran muy elevadas. En definitiva, no es un problema de simple supervivencia de las dictaduras, sino de inseguridad del Estado. En un marco en el que la amenaza de la guerra estaba permanentemente presente, en el que la guerra se había convertido en guerra total debido al arma atómica y en el que ya no era posible declararse neutral, salvo que así lo acordaran ambas superpotencias, cubrir las necesidades de seguridad era el objetivo esencial de cualquier Estado, independientemente de la naturaleza de su régimen político. En otras palabras, el giro de ambas dictaduras hacia los Estados Unidos era una necesidad elemental asociada al factor seguridad y a la propia división del mundo en dos bloques profundamente antagónicos.

\subsection{Los cambios en el sistema: la idea de interdependencia}

A mediados de los años cincuenta, el sistema internacional experimentó un cambio acelerado. Las dinámicas de cohesión de cada bloque generaron un potente impulso integracionista tanto en un ámbito global -occidental- como regional -europeo. Además, la disuasión del terror, basada en la necesidad de respuestas calculadas habida cuenta de que un enfrentamiento podía degenerar en la guerra atómica y, en definitiva, en la destrucción total de ambos contendientes, mantuvo la bipolaridad fuera de la confrontación militar directa. La racionalidad de la disuasión mutua, equilibrada mediante la técnica de la contención mutua, acabó estableciendo un modus vivendi basado en la teoría de la coexistencia. El problema de seguridad ya no era tanto afrontar la inminencia de una guerra de destrucción masiva, como asegurarse de que cada superpotencia se mantenía en su espacio delimitado. La competencia militar dejó paso a una competencia económica y tecnológica que acabó por transformar el sistema internacional. La idea de seguridad comenzó a dejar paso a la idea de interdependencia.

La interdependencia aludía a la existencia de una compleja red de interacciones entre una pluralidad de actores que se relacionan de forma cooperativa. El mundo, por tanto, dejó de ser visto como ese exclusivo espacio de anarquía y conflicto, para pasar a ser una entidad compleja con múltiples canales que interconexión entre las diferentes sociedades. Por tanto, la idea de autarquía y de desarroIlo autocentrado comenzó a dejar de tener sentido. En este nuevo mundo interconectado, los temas de la agenda internacional se multiplicaron, aunque lo fundamental fue la ausencia de jerarquía en la misma. O dicho de otra forma, la seguridad militar no dominaba ya consistentemente dicha agenda, por cuanto se había constatado que en situaciones de interdependencia compleja, la fuerza militar había dejado de ser un recurso a utilizar por los gobiernos. 
En este nuevo marco, los problemas fundamentales ya no eran exclusivamente los relativos a la seguridad, sino que cobraron extraordinaria importancia los factores sociales y económicos propios de un mundo desarrollado y cada vez más avanzado científica y tecnológicamente. Por tanto, las nuevas demandas que los Estados debían satisfacer se referían a relaciones comerciales y financieras, desarrollo tecnológico, problemas ecológicos, etc. En definitiva, problemas que cada vez escapaban más a las posibilidades individuales de cada Estado para poder satisfacerlas correctamente.

En esta nueva fase de interdependencia, los Estado debían abrirse y cooperar entre sí, pues cada vez existían un mayor número de regímenes internacionales en los que era necesario participar. Es decir, los Estados, y los autoritarismos ibéricos no constituían ninguna excepción, debían participar activamente en todo ese conjunto de principios, reglas y procedimientos de toma de decisiones que permitían que las expectativas de los actores convergieran en un tema concreto de las relaciones internacionales. Si no lo hacían así, el riesgo no era sólo el aislamiento de la dictadura, sino la separación del país de todas estas corrientes internacionales de cooperación.

Precisamente esta es la función que cumplieron los desarrollistas y liberalizadores de los autoritarismos ibéricos: engarzar a ambos países con ese tronco común del capitalismo desarrollado en una fase de interdependencia compleja. Y es en este aspecto en el que tuvieron más éxito, pues de manera general, los desarrollistas lograron orientar de forma definitiva la inserción internacional de ambos países dentro del marco de los países occidentales, que es evidentemente, su área natural de inserción.

Mucho menos éxito tuvieron al intentar dar respuestas a las nuevas corrientes ideológicas, artísticas y culturales que se desarrollaron a lo largo de los años sesenta. En general, estas nuevas corrientes y los nuevos movimientos sociales que las representaban, tendieron a cuestionar el racionalismo desmovilizador del Estado de bienestar, reivindicando una nueva radicalidad que tenía como fin romper los sistemas de orden y autoridad establecidos durante los años cuarenta. Evidentemente, los autoritarismo fueron incapaces de poder responder a estas nuevas demandas porque, simplemente, su universo mental conservador era de otra época y casi ya, de otro mundo.

\section{VISIONES, MENTALIDADES Y REALIDADES: ENTRE LA CONTINUIDAD Y EL CAMBIO}

\section{1. ¿Qué fueron los desarrollistas?}

Uno de los aspectos fundamentales en la interpretación de la etapa marcelista, y en la propia significación histórica de la figura de Marcelo Caetano, consiste en dilucidar si fue un periodo de continuidad que hizo que el cambio político sólo pu- 
diera venir por la vía disruptiva del golpe de Estado, o más bien fue un período de cambio que disgregó tanto los elementos de cohesión interna de la dictadura que ésta, finalmente, se desmoronó ante la presión que ejercieron los Capitanes de Abril.

De igual forma podríamos abordar el estudio del llamado tardo-franquismo, en el sentido de interpretar a los desarrollistas españoles como unos modernizadores predemocráticos, o como otros autores mantienen, considerarlos meros apuntaladores de la dictadura, que acudieron a simples formas cosméticas para garantizar la viabilidad del régimen y que, por lo tanto, no tuvieron influencia significativa en la transición democrática. Desde este punto de vista, la democracia sería un fruto ajeno a cualquier figura proveniente del régimen, incluso, más bien, sería el resultado de una soterrada lucha contra los elementos residuales de la dictadura.

La discusión se amplía, ya que en realidad, el debate de fondo se centra en considerar a los regímenes autoritarios como largas noches de oscuridad y represión, que simplemente impusieron un estático dominio represivo sobre las sociedades ibéricas, o admitir que los autoritarismos ibéricos tuvieron un carácter evolutivo y dinámico que les permitió resolver problemas socio-económicos históricos, o por lo menos diluir el carácter radicalmente conflictivo que éstos tuvieron décadas atrás, lo que, finalmente, acabó generando un conjunto de oportunidades democratizadoras que antes o después, y de una u otra forma, acabaron consolidando tanto en Portugal como en España un Estado social y democrático de derecho, plenamente asimilable a cualquier otro existente en el mundo occidental.

La discusión no es baladí, pues afecta a la significación de los procesos de transición en la medida en que lleva a rastrear sus raíces, al mismo tiempo que permite reflexionar acerca de sus impulsores y protagonistas. Si admitimos el carácter transformador de los modernizadores y liberalizadores de los autoritarismos ibéricos, es evidente que podríamos considerarlos como los verdaderos impulsores del cambio, admitiendo que fueron los propios regímenes los que acabaron creando mecanismos de apertura que llegaron a alterar de tal forma su propia naturaleza política que generaron, aunque fuera de forma involuntaria, antesalas de democracia, a la que se pudo llegar por uno u otro camino o a la que, si las circunstancias se hubieran tornado radicalmente adversas, simplemente no se hubiera llegado.

Además, podríamos deducir que aquellas transformaciones liberalizadoras que consiguen mayor éxito, allanan el camino para que el cambio político adopte fórmulas no rupturistas. Por el contrario, la ruptura vendría cuando a esas transformaciones se sobreponen algunos factores políticos tan fundamentales que llegan a cerrar esa puerta entreabierta por los desarrollistas a la democracia. En el caso portugués, sería, evidentemente, la guerra colonial, que impidió la evolución consensuada del régimen y de la oposición hacia la democracia y forzó la salida rupturista en forma de intervención militar. 
La interpretación se vuelve más difícil si partimos de la idea de que los liberalizadores fueron, al mismo tiempo, factores de continuidad y factores de cambio, lo que sólo se puede entender desde la perspectiva ideológica conservadora que todos ellos compartían, y desde el doble análisis de las motivaciones -plano en el que seguramente prima la idea de continuidad-, y, sobre todo, de los resultados, dónde seguramente, se impone la consideración del cambio.

\subsection{Las motivaciones del conservadurismo desarrollista}

Los desarrollistas de ambos lados de la frontera fueron liberalizadores, no liberales, incluso más bien se podrían definir como antiliberales. Su mundo era el del conservadurismo político inscrito en una cosmovisión religiosa de la vida que les llevaba a reconocer la existencia de un orden superior -natural- del que derivaba no sólo un orden trascendente, sino la afirmación de que la actividad política era una actividad moral, y que aquella estaba subordinada a ésta. En este sentido, partían de la consideración de que la política se orientaba hacia el bien común, -por muy segmentado e incluso cínico que este concepto pueda parecer, teniendo en cuenta la aceptación implícita de instrumentos de represión social. Sin embargo, estaban convencidos, y ese convencimiento era seguramente sincero, de actuar dentro de parámetros jurídicos y morales en la consecución de las mejores condiciones de vida para la mayoría de las personas.

Este es el sentido de su concepto de bien común, entendido como la consecución del conjunto de condiciones de vida que permitían a todas las personas su desarrollo personal. Y como marcaba la encíclica Rerum Novarum (1891) del Papa León XIII, el Estado debía asumir como misión propia la consecución del bien común. En consecuencia, la dimensión moral de la política consistía en utilizar los mecanismos del Estado para mejorar efectivamente la vida de las personas.

Esta expresión del bien común tenía otra dimensión concreta en el servicio al Estado, concebido como servicio a la patria, a la nación histórica a la cual pertenecían. Es este sentido de servicio el que explica las contradicciones y el indudable patetismo del desarrollismo políticamente fracasado que representa Marcelo Caetano. Es esta idea la que permite comprender el lado humano de quien sabiendo que estaba al borde del precipicio, seguía considerando que su obligación era seguir sirviendo a su país. Es este concepto de obligación moral, comprensible desde esa visión trascendente de la actividad política, el que explica el sentimiento de derrota que transmite el dictador portugués, pero es también desde esta perspectiva desde la que hay que entender al último Laureano López Rodó, aquel que desde el escaño obtenido en las filas de Alianza Popular acabó por renunciar a una actividad política que para él había perdido la significación de antaño.

El gran artífice del desarrollismo español acabó desligándose de la formación encabezada por Manuel Fraga por considerarse incompatible con algunos de los 
preceptos constitucionales que esta formación sí estaba dispuesta a aceptar, relativos a la familia, la unidad nacional, la educación o el modelo económico. Esta incompatibilidad era realmente de fondo, y reflejaba su incapacidad para aceptar el pluralismo real de la sociedad española y la necesidad básica de alcanzar consensos que permitieran la convivencia de todos y entre todos. Esto es, entender que la idea de bien común tenía que ser compartida y no unívocamente impuesta desde el poder y que tanto su concepción del bien común como los mecanismos para llegar a alcanzarlo podían ser muy diferentes a los que él mantenía y aceptaba.

En el fondo, demostraba que el conservadurismo de López Rodó, igual que el de Marcelo Caetano, era incompatible con el principio de pluralismo democrático de raíz liberal. La incompatibilidad se tornó, finalmente, en incomprensión de un mundo que había avanzado mucho más de los que ellos mismos habían imaginado, de ahí que en sus momentos finales admitieran con cierta amargura su incapacidad para ver, comprender y aceptar una sociedad que ellos ayudaron a crear, pero con la que difícilmente podían ya identificarse.

Y no podían hacerlo, porque los desarrollistas ibéricos no eran liberales, y mucho menos demócratas. Su idea de libertad era muy distinta a la de éstos. Su visión de la sociedad era una visión organicista, en la que el individuo encontraba su verdadero sentido dentro de un órgano colectivo construido históricamente de forma acumulativa en el tiempo y que se expresaba según un principio de representación limitada. La libertad se vinculaba al orden y a la estructura orgánica de la sociedad, basada en ese triángulo conformado por el Estado, el individuo y los cuerpos intermedios que colocaban a cada persona en su lugar natural y los relacionaba con el poder.

Evidentemente, su visión organicista les llevó a rechazar la idea del conflicto de clases como categoría socio-histórica específica. Su convicción era otra distinta. Para ellos, la sociedad era un cuerpo integrado en el que cada grupo social cumplía una función, siendo todas ellas necesarias para el buen funcionamiento del sistema en su conjunto. El principio esencial de orden era que el sistema se mantuviera en equilibrio, pues era éste el que garantizaba un desarrollo armónico del cuerpo social. Por eso consideraban imprescindible trabajar por un desarrollo social efectivo, pues aunque admitían el principio de desigualdad natural de los seres humanos, su visión moral y jurídica les llevaba al convencimiento de que las relaciones de desigualdad podrían generar condiciones de injusticia si estas salían de ese cauce considerado natural.

En este punto, el conservadurismo se había teñido hacía mucho de preocupación social, según el modelo de compromiso social de la Iglesia Católica que alumbrara la encíclica Rerum Novarum, seguida y completada en años posteriores por Pío XI, Juan XXIII y Pablo VI. La idea de justicia social acabó siendo fundamental en este impulso desarrollista, pues al estilo de Jaime Balmes, todos ellos partían de la idea de que la elevación del nivel de vida era un factor clave de equilibrio y estabilidad social, condiciones necesarias para el verdadero progreso. Y es- 
tos logros sólo eran posibles si existía un gobierno fuerte que evitara el conflicto y la anarquía. Seguramente tanto Marcelo Caetano como los demás desarrollistas de las dictaduras portuguesa y española estarían perfectamente de acuerdo con esta frase del sacerdote catalán: "sin poder no hay orden, sin orden no hay obediencia a las leyes, y sin obediencia a las leyes no hay libertad". ${ }^{1}$

El elemento central de toda esta construcción conservadora del mundo era la noción de orden. Pero en este punto el conservadurismo se había apartado hacía tiempo del tradicionalismo al admitir la idea de cambio y renunciar a una simplista vuelta a esa especie de mítica arcadia feliz con la que éstos recreaban el Antiguo Régimen. Los conservadores aceptaban el cambio, aunque siempre sobre la perspectiva de un cambio ordenado y controlado, y se habían adaptado ya a los problemas y realidades de la sociedad moderna, industrial y urbana. El cambio, por tanto, no sólo era aceptable, sino necesario, siempre y cuando sus ritmos fueran moderados y, sobre todo, controlables.

Pero el cambio tenía un límite en el ejercicio del poder. Cierto es que todos ellos buscaron una despersonalización de su ejercicio y la creación de una maquinaria administrativa eficiente y ampliamente despolitizada, pero estos objetivos tenían como fin satisfacer las necesidades de desarrollo social que, a su vez, era la garantía indispensable del mantenimiento de las estructuras políticas autoritarias. En modo alguno se plantearon su destrucción y su sustitución por un sistema plenamente democrático.

La obsesión por el orden suponía su aceptación de que el poder debía tener una función reguladora de la libertad individual y de la libre expresión, pues todo aquello que no fuera controlado, podría generar factores de desgobierno. La libertad debía ser vigilada porque en su opinión, acababa tarde o temprano amparando el desorden. Por eso aceptaban la censura e incluso la represión, pues no la consideraban como tal sino como un criterio de orden que mantenía controlados los cauces del desarrollo social. Este es el gran problema de los desarrollistas y liberalizadores, su alergia a la libertad de las personas, y su incapacidad para comprender que una sociedad atomizada, plural y libre puede ser mucho más estable y ordenada que una sociedad vigilada, por muy próspera que ésta sea. Aquí radica en gran medida su amargura final, pues fueron incapaces de comprender que una sociedad desarrollada, relativamente rica, quisiera la libertad que sólo la democracia podía satisfacer. La igualdad podía ser un logro sustancial, pero una gran parte de ciudadanos españoles y portugueses la consideraron condición necesaria pero no suficiente, demandando que a ella se añadiera la libertad y, evidentemente, esto era algo que el universo de los desarrollistas ibéricos no podía ofrecer.

Por el contrario, su gran acierto fue aceptar que la única posibilidad real de desarrollo era dentro del tronco común del capitalismo desarrollado. Y aquí es donde

1 BALMES, Jaime (1950): Obras completas, Madrid, BAC, T.VI, p. 86. 
reside uno de los criterios de separación más significativos entre la experiencia desarrollista española y portuguesa. La primera no sólo fue exitosa en sus resultados, sino también en la introducción acelerada de una economía mixta, pero esencialmente de mercado que aunque soportaba enormes rigideces, tenía ya todas las características propias de una economía occidental avanzada. Pero sobre todo, permitió que esa riqueza se repartiera efectivamente por amplísimas capas de la sociedad. Este éxito hizo que prácticamente nadie en España defendiera una alternativa radical a ese modelo de desarrollo capitalista. Sin embargo, en Portugal, a pesar de los enormes avances logrados por la política desarrollista, sus niveles de bienestar fueron comparativamente mucho más modestos, por lo que la impugnación del modelo socio-económico capitalista basado en una economía libre de mercado fue mucho mayor, lo que indudablemente repercutió en un menor consenso a la hora de establecer los marcos de transición que debía seguir el país tras la caída del autoritarismo.

En definitiva, el desarrollismo y la liberalización tuvieron un carácter instrumental, como fue mantener el régimen de orden que, en su opinión, generaban los regímenes autoritarios. Desde esta perspectiva, fueron evidentemente continuistas. Sin embargo, los enormes cambios que propiciaron y su insistencia en construir un marco institucional despolitizado, despersonalizado, burocratizado y regulado por una relación jurídica objetiva, abrió brechas de libertad que anunciaban posibilidades de cambio. Otra cosa es que estos preámbulos predemocráticos fueran acertadamente estimulados hasta generar situaciones reales y efectivas de cambio político. Y en esta labor los desarrollistas ocuparon un papel importante pero más secundario, pasando el protagonismo a nuevos actores políticos, sociales e institucionales que fueron los que acabaron efectivamente dirigiendo los procesos de transición a la democracia.

\subsection{Los resultados del desarrollismo}

La etapa final del franquismo supuso el salto modernizador más importante de toda la historia contemporánea de España y, lo que es más importante, supuso un cambio radical en los niveles reales de vida de una mayoría muy sustancial de españoles. España se convirtió en un país urbano, crecientemente secularizado y en el que las clases medias relativamente acomodadas podían tener una segunda residencia, un medio de locomoción propio e incluso realizar algunos gastos suntuosos impensables apenas treinta años atrás.

El tradicional campo español simplemente desapareció, y con él, todos los graves problemas históricos que conllevó la existencia de enormes masas campesinas en estado de semi-indigencia. Mientras el mundo rural alcanzaba un nivel de vida suficiente, la nueva masa obrera de las ciudades pudo disfrutar de un nivel económico mínimo aceptable mientras la población empleada en el sector servicios aumentó sin parar. La extraordinaria elevación de la renta propició una mejor dis- 
tribución de la misma, y aunque la desigualdad social continuó siendo significativa, ésta dejó de basarse en una polarización social extrema. La idea de lucha de clases desapareció de la realidad de las relaciones sociales, quedando confinada en el imaginario colectivo de algunos intelectuales muy alejados de la verdadera realidad social que mostraba el país.

Este criterio de realidad se impuso definitivamente en los movimientos obreros, que fueron convirtiéndose en factores de compromiso y consenso y no de confrontación. La idea de reforma se impuso definitivamente a la de revolución. La dicotomía capitalismo/socialismo desapareció y con ella las visiones profundamente ideologizadas que imaginaban caminos distintos hacia el bienestar. El desarrollismo autoritario asentó definitivamente el modelo capitalista aunque intervenido de acuerdo a una potente presencia dirigista por parte del Estado.

La elevación del nivel de vida de la mayoría de la población fue acompañado de una extensión comparativamente importante de las políticas de bienestar social. Los sistemas de seguros sociales y de protección de los trabajadores generaron una significativa percepción de seguridad, mientras la extensión de la educación en todos sus niveles fue también muy acusada.

Los avances no pueden esconder una realidad nacional todavía limitada, muy desigual en términos regionales, y bastante alejada de la media de los principales países de la Europa occidental. Sin embargo, comparándola con la realidad española de cuatro décadas atrás, el salto había sido muy importante.

La liberalización de la economía abrió el país a los capitales extranjeros, con lo que las posibilidades de inversión se ampliaron muy notablemente, pero sobre todo, animaron un proceso de innovación tecnológica limitado pero significativo. A estos recursos se añadieron los proporcionados por las remesas de los emigrantes, que además de proporcionar capital, aliviaron las tensiones del desempleo y facilitaron un proceso amplio de movilidad geográfica y social. El contacto económico con el exterior ayudó a transformar la mentalidad colectiva de los españoles. El extraordinario desarrollo del turismo cambió mentalidades, actitudes y comportamientos. La anterior atmósfera de cerrazón cultural comenzó a abrirse gracias a una relajación de la censura, lo que permitió que las nuevas generaciones de españoles participaran de forma significativa de las nuevas corrientes artísticas, cinematográficas o musicales y que pudieran acceder a los nuevos movimientos sociales y a las nuevas corrientes ideológicas que recorrieron el mundo occidental en los años sesenta y primeros setenta.

Fue, de hecho este contacto y esta apertura de la mentalidad colectiva lo que acrecentó la percepción de inadecuación entre una sociedad que ya comenzaba a manifestar valores más posmateriales que materiales y, en general, valores claramente democráticos, y una estructura político-institucional más propia de sociedades firmemente arraigadas en los valores materiales. Quizás el único valor material que prevalecía a mediados de los setenta era el del orden, y quizás, por ahí 
se pueda comprender que la oposición decidiera seguir una vía transaccional y de consenso como camino hacia la democracia. Por eso la transición española no se vio irreversiblemente afectada por el rápido y profundo deterioro de la situación económica. La sociedad española había evolucionado lo suficiente como para establecer sus criterios de legitimidad por encima de las coyunturas económicas, por lo que no se estableció, salvo casos muy aislados, ninguna relación causal entre la crisis económica, la crisis final del franquismo y el comienzo de la nueva etapa democrática.

En definitiva, el desarrollismo autoritario español cumplió ampliamente los objetivos que se marcó a mediados de los años cincuenta. En 1973 la renta per cápita de los españoles sobrepasaba ya los 2000 dólares, cifra mágica que los propios desarrollistas habían puesto para que pudiera haber una evolución política ordenada, controlada y estable. Pero aunque la realidad sucediera efectivamente así, no demuestra que estuvieran en lo cierto. La crisis de gobierno obligada por el asesinato del Almirante Carrero Blanco inició un potente giro involucionista que supuso la práctica desaparición de los desarrollistas del gobierno y de los altos cargos de la administración. $Y$ nada permite afirmar que las contradicciones entre el efímero espíritu de febrero de Carlos Arias Navarro y su apuesta por la dureza inmovilista no hubiera podido prolongarse si la vida de Franco no se hubiera extinguido apenas unos meses después y, sobre todo, si el rey Juan Carlos I no hubiera optado por una solución arriesgada y difícil como fue la sustitución de Arias $\mathrm{Na}$ varro - que parecía querer protagonizar una especie de marcelismo a la española- por Adolfo Suárez.

El desarrollismo portugués fue mucho menos exitoso en términos absolutos, que no en términos relativos. La renta per cápita portuguesa había alcanzado en 1973 - ¿sólo? - 1158 dólares, lo que seguía dejando al país a la cola de las naciones de la Europa occidental. Sin embargo, el desarrollo portugués había sido muy intenso en los años sesenta y, especialmente, durante la etapa de gobierno de Marcelo Caetano, empujado por su cada vez mayor integración del país en la economía de la Europa comunitaria.

El desarrollo portugués animó un amplio proceso de urbanización y desruralización, pero el peso del mundo campesino en la economía y en la sociedad portuguesa siguió siendo importante. La persistencia de una agricultura minifundista impidió una reconversión capitalista completa, lo que repercutió en unos niveles de renta sensiblemente bajos. Del mismo modo, Portugal experimentó en esos años un incesante desarrollo del sector servicios que transformó la estructura económica del país. Pero la persistencia de grandes monopolios industriales y financieros concentró en exceso la renta e impidió una redistribución más equitativa de la misma. Los niveles medios de vida se elevaron significativamente, pero continuaron existiendo amplias capas de la población en la raya de la subsistencia. Evidentemente el Portugal de mediados de los años setenta poco tenía que ver con el de los años treinta, pero el nivel de vida no había mejorado tanto como para que las 
ideas y valores asociados al concepto de calidad de vida se impusieran ampliamente sobre los valores de seguridad material.

También se elevaron notablemente los niveles educativos, especialmente en el nivel universitario, que vio multiplicarse por cuatro el número de estudiantes en apenas quince años. La mejor educación fue un factor decisivo para el cambio de las mentalidades colectivas, al permitir incorporar a los puestos de responsabilidad a nuevas generaciones técnicamente bien formadas y con una mentalidad política muy diferente a aquella que el régimen seguía intentando socializar. Junto a la educación, se extendieron otros medios culturales como el cine, la televisión o la música, que ayudaron también a extender entre la población esas nuevas corrientes sociales e ideológicas que iniciadas en los sesenta se encontraban a mediados de los setenta en pleno apogeo.

La capacidad redistributiva del Estado continuó siendo baja, tanto en un sentido individual como territorial, por lo que las grandes diferencias continuaron. También fue limitada la extensión de un sistema social amplio, lo que hizo que la sensación de seguridad fuera en Portugal sensiblemente menor que en España.

Esta percepción de menor desarrollo se incrementó por el efecto emulador de la emigración y el turismo, que igual que fueron factores fundamentales de progreso y de apertura social, también sirvieron para aumentar las expectativas sociales -el mito europeo- y las demandas para que el desarrollo llegara extensamente a todos. Por eso en Portugal se dieron mayores elementos de impugnación hacia el modelo liberal capitalista y persistieron entre amplios grupos sociales los mitos movilizadores socializantes.

De todas formas, la persistencia de estos mitos no impidió que en lo sustancial, los cambios socioeconómicos dibujaran a mediados de los años setenta una sociedad impregnada de valores democráticos y una estructura potencialmente estabilizadora, aunque con algunas asimetrías muy importantes, para un cambio político ordenado. Sin embargo, el problema no fue tanto la limitación en los niveles de desarrollo alcanzados como políticos. El desarrollismo luso no pudo encontrar solución al gran problema político en el que se debatía el régimen desde hacía muchos años: la guerra colonial. A la altura de 1970, no existía posibilidad de continuar el proceso de liberalización y modernización sin solucionar el problema colonial. La contradicción era que si se daba esa solución, la liberalización y la modernización corrían el riesgo de no poder resistir la presión de las corrientes más duras que seguían ancladas al paradigma colonial como elemento definidor de la esencia del autoritarismo.

\section{A MODO DE CONCLUSIÓN: LOS TIEMPOS}

La diferencia sustancial entre ambos proyectos fue, esencialmente, de tiempos. El desarrollismo español apareció en un momento fundamental, especialmente 
oportuno, pues el régimen autoritario era incapaz de responder en esos momentos finales de los años cincuenta, a las nuevas demandas planteadas por un sistema internacional en mutación manteniendo las estructuras socioeconómicas vigentes hasta entonces. Consiguió imponerse también, porque apareció en un momento clave del proceso de institucionalización de la dictadura, en el que el propio Franco fue consciente de la imposibilidad de recorrer el futuro por las vías de un falangismo hacía mucho agonizante. El desarrollismo apareció así como nueva expresión de consenso, imprescindible para relegitimar el régimen autoritario sobre unos elementos materiales habida cuenta del paulatino desgaste de las lealtades de base ideológica y el agotamiento de las posibilidades de seguir recurriendo masivamente a métodos coactivos.

En Portugal, sin embargo, el desarrollismo de Marcelo Caetano llegó por lo menos, una década tarde. La liberalización del último dictador luso hubiera podido triunfar en los años cuarenta, incluso en 1958 o 1961, pero era un discurso y un proyecto agotados en 1968. Las expectativas sociales y las demandas ciudadanas eran ya otras y la persistencia de una guerra colonial cada vez más impopular impedía aceptar soluciones de compromiso. Al contrario que en España, el marcelismo apareció como una especie de corriente crítica y alternativa a la ortodoxia salazarista y al poder personal del que fuera durante tantos años presidente del Consejo de ministros. Al fracasar la vía de incorporación selectiva de parte de la oposición al marco político-institucional del Estado Novo, esta corriente pasó a desempeñar unas funciones que ni podían hacer, ni estaban preparados para realizar. Cuando por fin se abrió su oportunidad, la liberalización y la modernización del país habían sido ya, por lo menos en parte, realizada por otros protagonistas. La única solución era, tal y como le demandaron los sectores liberales que se incorporaron al régimen a partir de 1970, avanzar decididamente hacia una transición ordenada pero con una meta clara: la democracia. Y evidentemente, era algo que Marcelo Caetano no podía hacer. Por eso, se quedó en un patético término medio: incapaz de continuar sin cambiar, e incapaz, también, de cambiar, pues su verdadera razón de ser era la continuidad. 